\title{
Dynamic global infrastructure: The freeport as value chain
}

\author{
Kathleen Ditzig \\ Independent researcher, Singapore/OFFSHOREART.CO
}

\section{Robin Lynch}

McGill University, Canada/OFFSHOREART.CO

\section{Debbie Ding}

Visual artist, Singapore/OFFSHOREART.CO

\section{Introduction}

In an interview with China Daily in 2014, Wang Yudong, director of the art trade centre at the Beijing Culture Free Port, declared: "We have mapped out a global free-port strategy. Our aim is to build an art free-port network in Asia" (Deng, 2014: para. 5). Facilitated by state partners from Geneva to Singapore, Luxembourg, Germany, Paris and the state-affiliated Beijing Gehua Cultural Development Group of the Beijing Freeport of Culture, freeports are believed by many governmental organisations to be a fast-track to a more mature and sustainable art market. In broad terms, freeports are special customs areas, or small customs territories, in which customs regulations are generally less strict, or for which there are no customs duties. Though each freeport varies slightly in terms of its individual jurisdictional arrangement with the respective states, they have established themselves as prominent nodes for international wealth and its traffic. They are also self-proclaimed logistics hubs that actively build networks and infrastructures across multiple jurisdictions, institutions of various kinds, and geographies. A more 'mature' art market in the eyes of states supporting freeports therefore means a market that is loosely regulated and which acts as a node to markets in other jurisdictions and as an attractor of global capital flows.

As we will show via a closer examination of the Luxembourg-based 'Le Freeport', the freeport is a value-creating operation. More specifically, as a company and network, Le Freeport is indicative of an almost inevitable mutation in the art market's infrastructure, allowing for even further mobility and self-regulation of a particular exclusionary level within the art market. To be clear, freeports are not a proprietary asset of the Le Freeport firm. Other companies such as Art Heritage Singapore, Euroasia Investment SA, Natural Le Coultre, or the Beijing Culture Free Port are also rapidly forming a new infrastructure and network of freezone spaces for the storage and movement of art and luxury goods. The special status of freeports 
has, to no surprise, seen them become an object of imagination and curiosity in the art world, with prominent names and institutions such as Hito Steyerl and the e-flux journal presenting visions and reports of the freeport as an obscuring mechanism for the elite, and as a speculative storage hub for accumulating value (see Steyerl, 2015; Heidenreich, 2015). While there is no doubt that freeports enable value-creating mechanisms through a consolidated network of systems and associations, the static view of the Freeport common to these criticisms - as a vaulted private bank hiding away and accruing value in assets such as art - is a misrepresentation of their dynamic infrastructural network and operational processes. Such views are not restricted to critical writing in the art field either. The Economist (2013) has also featured similar arguments.

The reality of freeports is however less opaque than mainstream critical narratives would have us believe. For example, though The Economist article prompted Singaporean authorities to undertake an inaugural national risk assessment report on money laundering and terrorist financing risks associated with the then newly-established freeport in that jurisdiction, the assessment did not find any fault with Le Freeport or a lack of transparency in its operations.

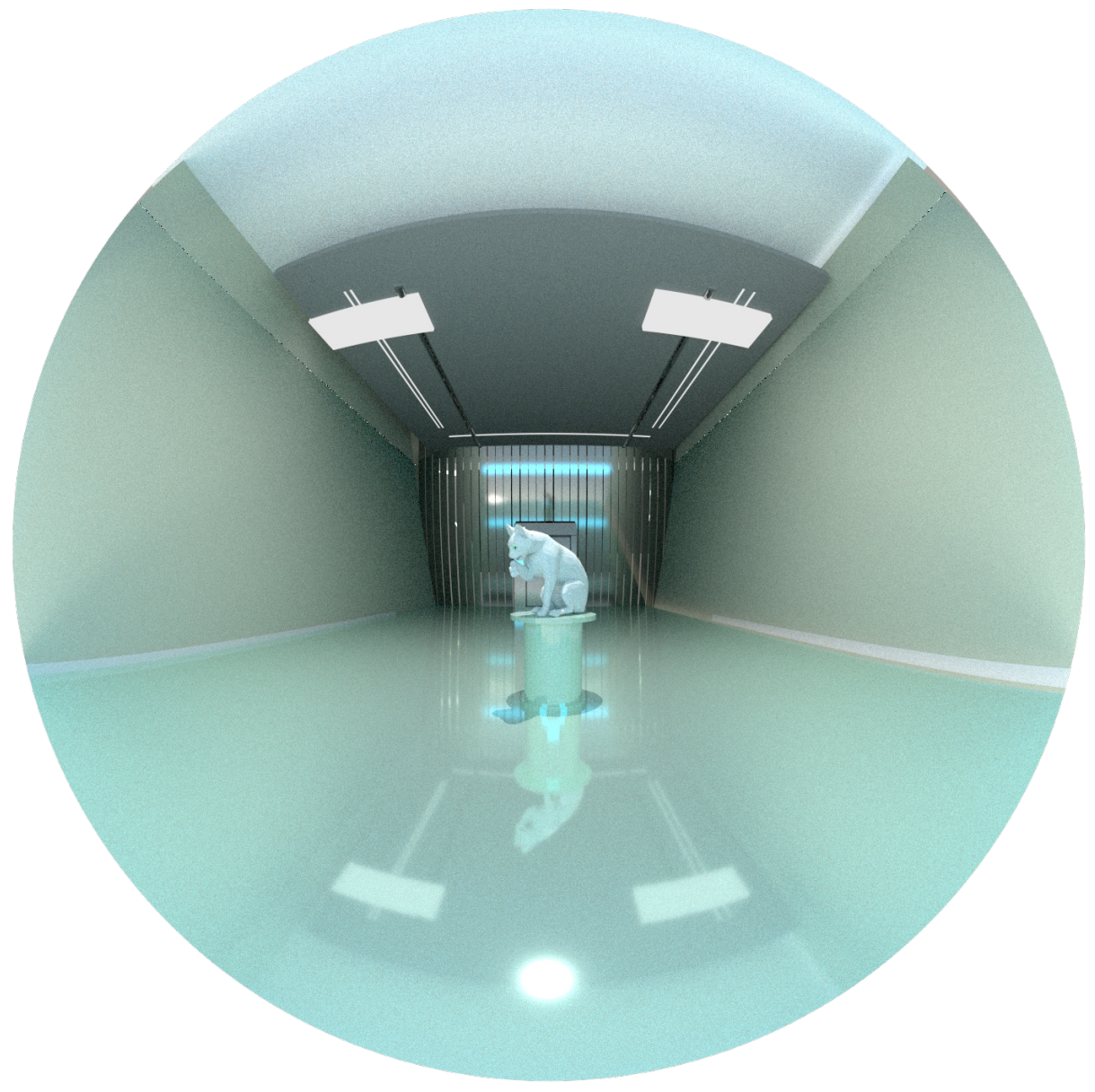

Figure 1. Cat. Image: Debbie Ding/OFFSHOREART.CO

Freeports are often presented as obscuring mechanisms serving the elite - a speculative storage hub for accumulating value where art or assets are like Schrödinger's cats, possibly existing within the 'box' or 'freeport' (or perhaps not), but accruing value through speculation. 
Simplistic visions of warehouses as magic boxes are, rather, a product of a desire to fetishise the freeport as an almost mythical space of abstract capitalism. What must instead be understood is that the freeport's mechanism of value creation is based not on what is actually stored within it, but on its relationship to regulated global markets. For example, in June 2014, market analysts predicted a rise in platinum prices following a five-month strike in South Africa. Though the eventual price increase was conspicuously small, it transpired that a major factor in market trading over the period was uncertainty over how much platinum was resting in the world's freeports (Antonioli and Denina, 2016). It was unclear if this was a coincidental by-product of conservative investments or deliberate market manipulation, but what it did make evident was that prices of a vendible good can be kept low or high depending on publicly available information about the availability of supply in freeports.

Broadly put, freeports are a value-creating operation. They have been established as prominent nodes for international wealth and traffic, but also as self-advertised logistics hubs that actively draw from and build networks and infrastructures across multiple jurisdictions, institution types and geographies. From the strategic selection of freeport locations to strengthen regional demarcation, to developing a 'one-stop shop' for collectors and art funds connected to wealth management facilities and cultural institutions, to the exclusive networks that can be tapped by those in the know within their inner circle of users and facilitators, freeports create a vast web of value chains that can be activated and deactivated at will.

\section{Perfecting the cluster}

Le Freeport is perhaps the most potent example of this creation of infrastructure. As a company and network, Luxembourg-based Le Freeport is emblematic of a diversification in the art market's infrastructure, allowing for yet further mobility and financialisation of a particularly exclusive sector of the art market. Through the aid of the state and the consulting firm Deloitte, which provided the development plan to diversify Luxembourg's economy in 2014 and make it an art logistics hub, Le Freeport was designed to develop alongside a system of galleries, wealth management facilities, an art fair and museums within a designated 'freezone'. Defining the zone as an "art cluster", the Deloitte Art and Finance Report (2014: 86) further highlights the dialogue of Le Freeport with private banks, stating that " $53 \%$ of private banks would advise their existing clients to make use of a freeport facility". Contrary to the critical narrative regarding freeports, the development of an "art cluster' does not simply suggest a static holding of luxury goods and art but rather the creation of a tax-friendly zone for trading, moving, flipping and collecting. Institution, fund and individual alike can utilise the freeport's high-tech facilities and logistics as they need, taking advantage of the infrastructure provided to create value for their works and, simultaneously, reducing the risk of fraudulent works being bought or works deteriorating in value because of poor storage conditions.

In its material construction, Le Freeport is a 22,000 square-metre building that opened in 2014. It is one of the latest freeports to join a global network of 'one stop shop' warehouses owned by a company previously known as Singapore Freeport and renamed as Le Freeport with the opening of the Luxembourg facility (Le Freeport, 2016). Artworks held within the walls of the facility are exempt from tax, which can be as high as $27 \%$ in Europe. Art sales within the building are also tax-free. Theoretically, art can remain in a freeport for years, through multiple transfers of ownership. Clusters for Logistics, a Luxembourg collective that focuses on developing the competitiveness of the country's global logistics sector, explains how the 
Luxembourg Freeport operates:

It will be a one stop shop, where end costumers will be able to have their works displayed in sophisticated private showrooms, photographed for inclusion in catalogues, crated for transportation, framed, restored, valued, insured, analysed to determine their origin or history, all of which without having to move the goods from the facility. End costumers are collectors, investors, museums, family offices, investment funds and others in need of high security storage and high-end services. (Anon., 2016)

Already evident within this description is that a carefully crafted ecosystem has to be created to maximise the value of Le Freeport's holdings, centralising all the necessary resources for flipping and storing works. Viewed within this framework, and given the rising interest in art as an alternative investment asset after the crisis of 2008, the freeport becomes a particularly attractive mechanism for investors in the art market.

Historically, the overall success of art as an asset class, or art funds in general, has been fairly limited. This is partly due to the high volatility of the art market itself, coupled with an opacity linked to lack of information on sales, and an inability to regulate pricing. Alongside the opaque and unregulated nature of the art market, Deloitte (2012: 14) claims that the most frequent disincentives for investing in art are the high costs of storage, insurance, and handling. These steep maintenance costs make for a very large expenditure cost for investors, which only lessens their possible returns. Against these drawbacks, and by marketing Le Freeport as a high-tech logistics and handling centre dedicated to art and luxury goods, the facility counters some of the key deterrents for investors. As a one-stop-shop logistics centre, Le Freeport offers a solution to storage and handling problems while conveniently connecting any asset to a potential network of buyers. Le Freeport is thereby at once a particularly attractive mechanism for investors in art and a transformative step in the material organisation of the art sector.

The strategic locations selected for the freeports are a clear indication of Le Freeport's role as an active mobiliser of infrastructure. As previously mentioned, freeports are granted their initial exceptional status due to their location within freezones. The freezone has a historical connection with global trade, finance, and industry. Designating freezones an "extrastate craft", Keller Easterling's (2012) account of these areas is particularly useful for tracing their development as major players in trade history. These zones are strategic and important landmarks for both the state, on whose peripheries the zones are placed, but also as key players within a more global framework. Through its lucrative status as an enabler of both economic and mobile freedom, the freezone has become a beacon and a nexus for international corporations and trade, embodying and facilitating an increasingly internationalised world of free trade. By positioning freeports within these already very active zones, Le Freeport taps into a mobile network of finance, trade, and exception, setting itself up as a highly-connected nodal point. 


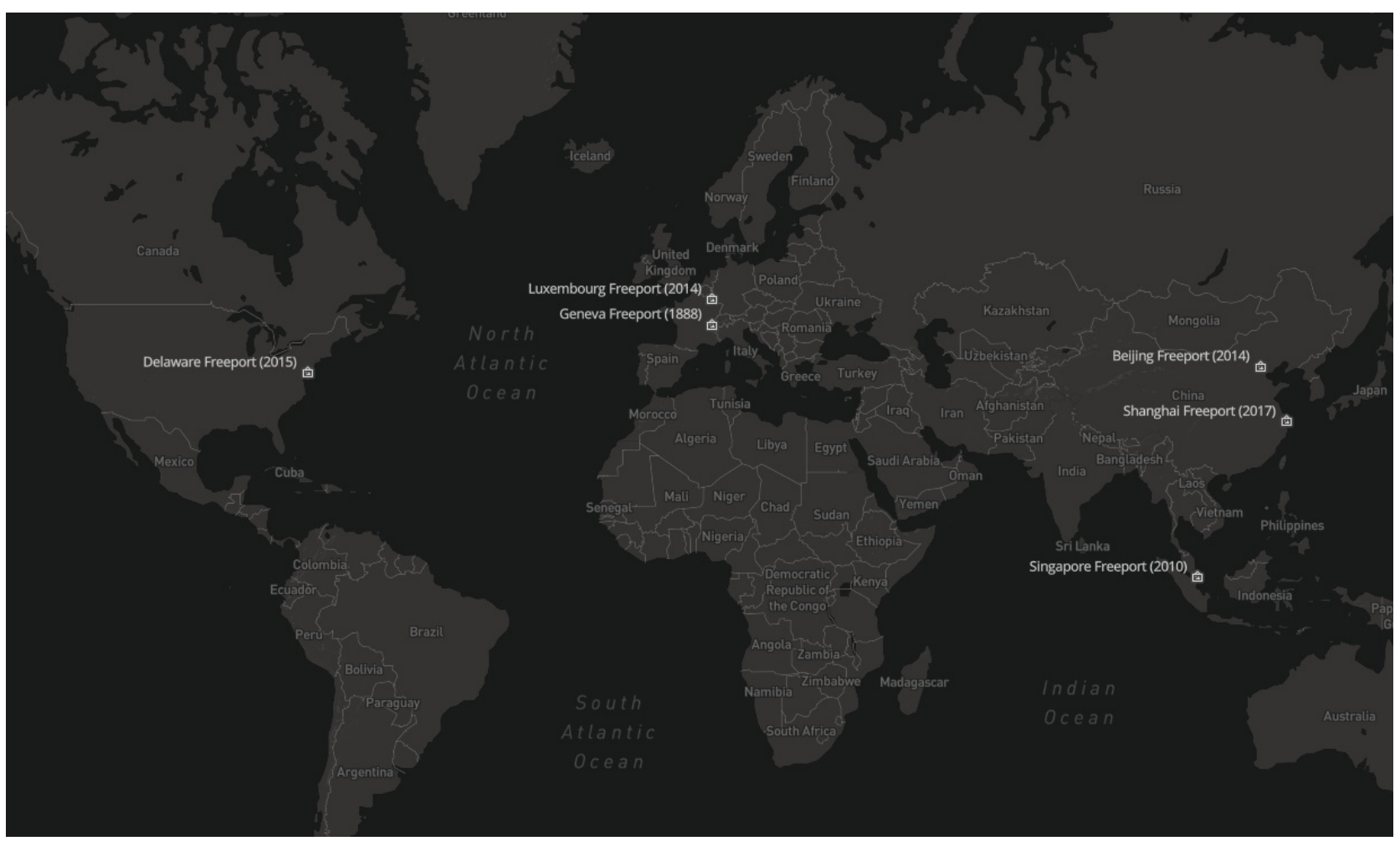

Figure 2. Map. Image: Debbie Ding/OFFSHOREART.CO

Map provides a visual representation of key freeports with the years in which they were established.

\section{The freeport's value chains}

It would be misleading, however, to say that Le Freeport's criteria for choosing a location is primarily that of its freezone status. It is no coincidence that the company's three operational freeports happen to be in locations known for wealth management, external trade and foreign investment. This is especially true given Le Freeport's established relationship with banks and investment funds. The company's initial move from Geneva to Singapore and to Luxembourg is a further indicator of their selective tapping into friendly legal zones for their services. It is worth noting that the Singapore government did not invite Le Freeport to set up within their state. Rather, the founders sought the support of the government. Furthermore, the interest in locating Le Freeport in Singapore was motivated by Swiss regulatory and tax reform in 2005. Prompted by scandals and foreign criminal cases involving the trafficking of stolen works, Switzerland enacted strict federal legislation based on a 1970 UNESCO international convention against art and antiquities trafficking. Thus, many of the freedoms afforded by the Swiss legislations began to be revoked, making it a less appealing freezone (Lankarani, 2009).

Not only are the freeports set up purposefully in areas that are already significant international centres of investment and trade, host states are also complicit in making the legal infrastructure that benefit the freeport. As with the extension of the tariff exception of the freeport being extended to museums in Singapore to promote exhibitions of the freeport's contents, Le Freeport sets itself up to create value through connections and networks across the social and cultural space. Items from its holdings can accrue cultural value thanks to their advantageous financial conditions for exhibition and circulation throughout major museums, thereby increasing their overall market value. 
The structural and contractual opacity of the art sector makes it difficult to track how these interconnected chains of monetary and cultural value are constructed across institutions. However, one such concatenation can be identified and provides a telling example. From May 2015 to April 2016, the Singapore Pinacotheque de Paris showcased collections of mainly European blue-chip works from private collections. It was run by Art Heritage Singapore, a company set up by Marc Restellini, the director of Pinacotheque Paris, along with Yves Bouvier and Alain Vandenborre, who are both shareholders in the Singapore Freeport. One look at the stakeholders and investors in the Pinacotheque, and the network for value creation tied to the freeport becomes apparent. In an interview with Art Blouin, Restellini said that Singapore's location makes it easier for Pinacotheque's Asian collectors to loan artworks to the Asian branch of the museum, pointing to yet another network creating mechanism in relation to the freeport (Chia, 2013). Furthermore, early reports on the establishment of Art Stage Singapore in 2010, a key regional art fair, identified the creation of the precursor to Le Freeport as a crucial contributing factor (Xinmo, 2015). Dias (2010: para. 3 ) writes that "[t]hanks to the new Freeport and Singapore's substantial subsidies, the ink is hardly dry on the promotional materials for Art Stage Singapore". With its ties to Le Freeport and finance, it is unsurprising that Art Stage Singapore has been described as the "premier art fair of the region" (Deloitte, 2016: 45). Such chains of institutional cross-support, however, are not always successful. By December 2015, Pinacotheque Paris was reported to be in receivership with plans to move its assets to Singapore, and by April 2016 its Singapore offshoot had also closed.

Nonetheless, even with its occasional failures, the importance of such networks of transactions in the market-driven transformation of the art sector cannot be understated. In the 2014 Art and Finance Report (Deloitte, 2014: 46-7), Le Freeport was judged to be a key driver of growth in the Southeast Asian art market. This is a problematic label, though, as the freeport is actually composed of a number of self-sustained national markets that do not span across the entire region. With its host of services and value chains, the Singapore Freeport consolidates the regional market as an infrastructural node that is oriented as much towards setting up deals as it is exhibitions. The networks of freeports are however internationally facing, and signal a strategy of cultivating foreign capital flows into the countries in which they are situated.

Freeports are also a potent soft power tool for countries, as they not only attract economic flows but also offer other lucrative benefits by creating funnel points for cultural networks, and projecting an image of technological and logistical expertise. The clear aim of Le Freeport's facility tour video (2016) is to showcase its architecture, which is not only ideal for its operations and unique security concerns, but is also aesthetically futuristic, sleek, and highly designed, demonstrating the importance of high-tech imagery and branding for developing its network. Similarly, one of the policies being developed at the Beijing Freeport of Culture is the building of an offshore financial market to serve cultural companies. Financial institutions will set up outlets for foreign exchange settlement, currency exchange and tax clearance services in freeports. Along these lines, the Chinese government is reported to have granted offshore cultural investment funds the right to allow foreign investors fewer limitations in investing in China's cultural industry. Though this seems a paradoxical policy move for a country known for its authoritarian control, and given that offshore infrastructure has historically been a way in which private individuals have protected their wealth from state purview, it should be seen as a strategic policy move that takes advantage of freeports as tools for competing in a global market. 


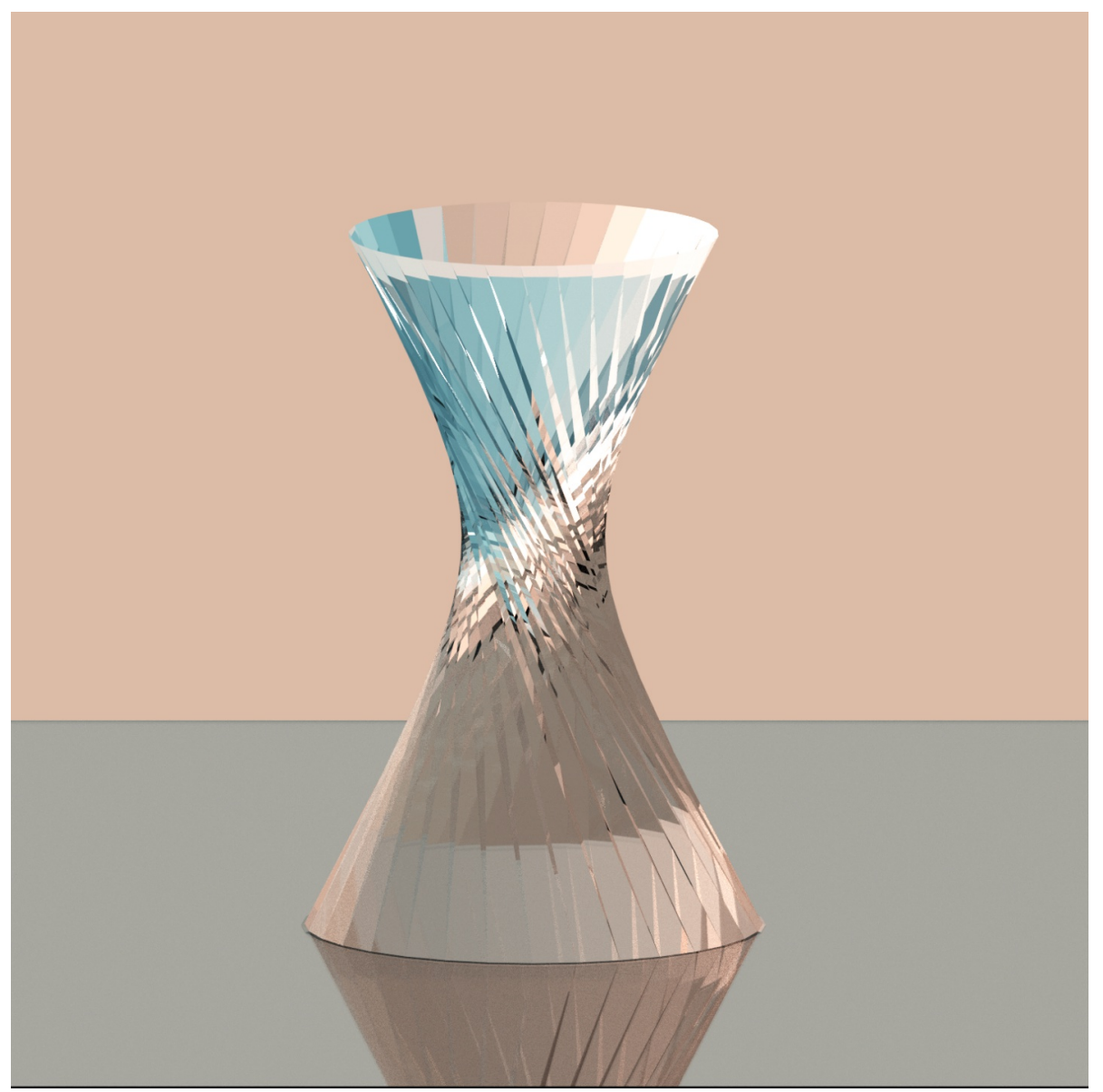

Figure 3. Defigure. Image courtesy of Debbie Ding/OFFSHOREART.CO

Defigure is a rendering of a spatial monument to replace the prevalent representation of the Freeport as wooden coffin and stylised warehouse. Made with glass and mirror or chrome, the monument's materiality inherently doubles by light passing through it or refracting against it, at times also making it invisible. These objects have no end or beginning, representative of networks communicating messages without interruption. Defigure is inherently empty, demarcating space for communication and a surface for transaction.

\section{The freeport is more than just a 'box'}

Based on their histories and geopolitical contexts, as well as their role in dispersing responsibility across distributed networks of capitalisation, freeports are much like other offshore infrastructure - such as shell companies housed in foreign jurisdictions. Both are mere mechanisms that have emerged through a long history of global financialisation and securitisation. They are amoral tools. Consequently, they can be sharpened by the state or informed individuals to become economic weapons able to steal, attack or defend capital.

In their expansive and networked chain of companies across a mapped globe, freeports represent a series of interconnected and flexible limited liabilities. Even if one branch of a network fails and needs to be restructured, the network is able to recalibrate to survive the ebbs and flows of information or capital in the market, moving one chairman out of view for another, creating one offshoot to support another, replacing a storage unit with a museum. Far from being a mere box or coffin for art, as the standard critical view holds, the freeport system is lively and flexible; an opportunistically activating and connecting set of infrastructures rapidly enable the freeport to become an integral tool in global trade - so long as state and private interests align. 
Mapping the interdependent in-state and offshore networks of companies and associations that emanate from a freeport demonstrates that they are a series of active processes based first on information flows, and second, on capital flows. Being able to guide and structure these flows is the ability to create value - and to destroy it too.

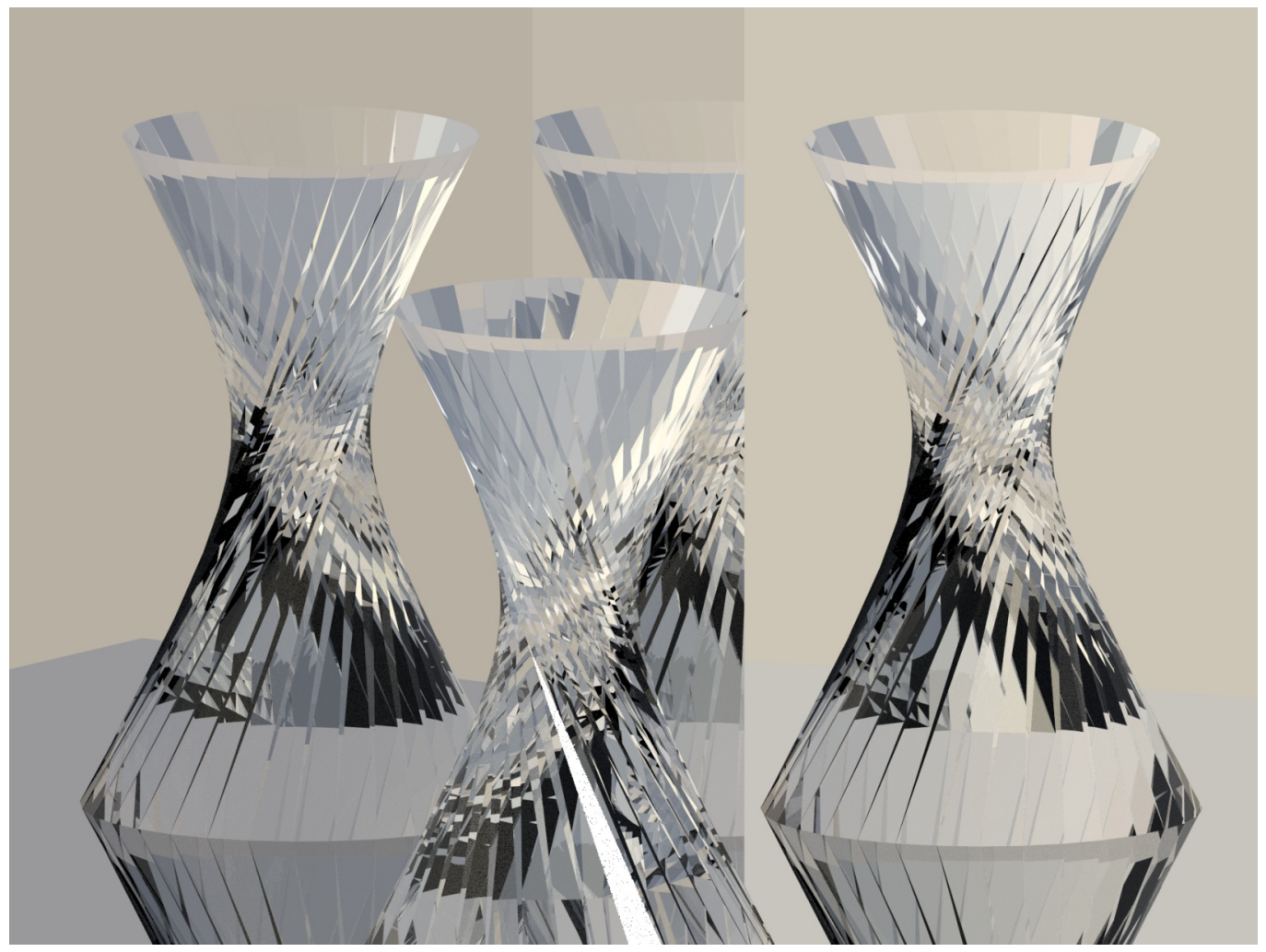

Figure 4. Defigure. Image courtesy of Debbie Ding/OFFSHOREART.CO

Defigure is an architecture embodying the offshore and its function in a global infrastructure. The hyperboloid grid-shell is a one-way system that shifts into two systems through a network of straight beams that appear to curve. Although visually splintered, the spatial monument is not constructed of fragments; rather it is one object with pieces linked together.

OFFSHOREART.CO is a platform and website that analyses offshore economies in order to understand global infrastructures and the narratives that support them. For more information visit http://offshoreart.co/

\section{References}

Anonymous (n.d.) Le FREEPORT. Cluster for Logistics. Available at:

<http://www.clusterforlogistics.lu/members/members-list/member-detail/logistics/theluxembourg-freeport/>. Accessed 4 April 2016.

Antonioli, S. and Denina, C. (2014) Secretive Swiss vaults may hold missing link in platinum price equation. Reuters UK [Online], 25 June. Available at: <http://uk.reuters.com/article/platinumfreilager-idUKL6NOP63S120140625/>. Accessed 3 April 2016.

Chia, A. (2013) Modigliani to kick off Singapore's Pinacotheque. Blouin Art Info Southeast Asia, 29 May. Available at: <http://sea.blouinartinfo.com/news/story/908387/modigliani-to-kick-offsingapores-pinacotheque/>. Accessed 13 September 2016. 
Deloitte and ArtTactic (2014) Deloitte Art and Finance Report. Available at: <http://www2.deloitte.com/content/dam/Deloitte/at/Documents/Tax/art-finance-report.pdf/>. Accessed 15 October 2016.

Deloitte and ArtTactic (2016) Art and Finance Report. Available at: <https://www2.deloitte.com/lu/en/pages/art-finance/articles/art-finance-report.html/>. Accessed 31 October 2016.

Deng, Z. (2014) Beijing Culture Free Port poised for art market. China Daily, 24 September. Available at: <http://www.chinadaily.com.cn/beijing/2014-09/24/content_18651539_2.htm/>. Accessed 3 April 2016.

Dias, C. (2010) Singapore, the new team player for the art world. Moda Vivendi, 14 June. Available at: <http://www.modavivendi.com/?p=1142/>. Accessed 1 September 2016.

Easterling, K. (2012) Zone: The spatial softwares of extrastatecraft. Places, June. Available at: $<$ https://placesjournal.org/article/zone-the-spatial-softwares-of-extrastatecraft/>. Accessed 3 April 2016.

The Economist (2013) Über-warehouses for the ultra-rich. The Economist, 23 November. Available at: <http://www.economist.com/news/briefing/21590353-ever-more-wealth-being-parked-fancystorage-facilities-some-customers-they-are/>. Accessed 3 April 2016.

Heidenreich, S. (2016) Freeportism as style and ideology: Post-Internet and speculative realism, part 1. e-flux, 71 (March). Available at: <http://www.e-flux.com/journal/71/60521/freeportism-as-styleand-ideology-post-internet-and-speculative-realism-part-i/>. Accessed 1 November 2016.

Lankarani, N. (2009) A new concept in handling art. The New York Times, 9 June. Available at: <http://www.nytimes.com/2009/06/10/arts/10iht-rcartoff/>. Accessed 3 April 2016.

Le Freeport (2016) Le Freeport in a Few Words [Video]. Available at: <http://www.lefreeport.com/>. Accessed 21 October 2016.

Le Freeport (2016) Le Freeport Singapore [Video]. Available at: <https://www.youtube.com/watch?v=WD91GCv8So0/>. Accessed 30 October 2016.

Picinati di Torcello, A. (2012) Why should art be considered an asset class? Deloitte Luxembourg. Available at: <https://www2.deloitte.com/content/dam/Deloitte/lu/Documents/financialservices/artandfinance/lu-art-asset-class-122012.pdf/>. Accessed 30 October 2016.

Steyerl, H. (2015) Duty-free art. e-flux, 63 (March). Available at: <http://www.eflux.com/journal/63/60894/duty-free-art/>. Accessed 1 November 2016.

Xinmo, Z. (2015) Why Beijing Culture Free Port will get more policy support. Ejinsight, 31 August. Available at: <http://www.ejinsight.com/20150831-why-beijing-culture-free-port-will-get-morepolicy-support/>. Accessed 2 September 2016. 